Article

\title{
Protective Effects of the Key Compounds Isolated from Corni fructus against $\beta$-Amyloid-Induced Neurotoxicity in PC12 Cells
}

\author{
Seung-Young Hong ${ }^{1, \dagger}$, Woo-Sik Jeong ${ }^{2, \dagger}$ and Mira Jun ${ }^{1, *}$ \\ 1 Department of Food Science and Nutrition, Dong-A University, Busan 604-714, Korea; \\ E-Mail: aseung02@hanmail.net \\ 2 Department of Food \& Life Sciences, Inje University, Gimhae, Gyeongnam 621-749, Korea; \\ E-Mail: jeongws@inje.ac.kr
}

$\dagger$ These authors contributed equally to this work.

* Author to whom correspondence should be addressed; E-Mail: mjun@dau.ac.kr; Tel.: +82-51-200-7323; Fax: +82-51-200-7535.

Received: 16 July 2012; in revised form: 1 September 2012 / Accepted: 5 September 2012 /

Published: 10 September 2012

\begin{abstract}
Amyloid $(\mathrm{A} \beta)$ peptide is the major component of senile plaques and is considered to have a causal role in the development and progression of Alzheimer's disease (AD). There is compelling evidence supporting the notion that $A \beta$-induced cytotoxicity is mediated though the generation of ROS. In the present study, we investigated the neuroprotective effects of ursolic acid (UA), $p$-coumaric acid ( $p$-CA), and gallic acid (GA) isolated from Corni fructus (CF) against $\mathrm{A} \beta(25-35)$-induced toxicity in $\mathrm{PC} 12$ cell. Exposure of PC12 cells to $50 \mu \mathrm{M} \mathrm{A} \beta(25-35)$ increased cellular oxidative stress, the number of apoptotic cells and caspase- 3 activity and finally caused significant cell death. However, UA, $p$-CA, and GA not only suppressed the generation of ROS but also attenuated DNA fragmentation and eventually attenuated $A \beta$-induced apoptosis in a dose-dependent manner. In protecting cells against $\mathrm{A} \beta$ neurotoxicity, UA and GA possessed stronger ability against ROS generation than $p$-CA, while $p$-CA showed the strongest anti-apoptotic activity. Particularly, $p$-CA protected cells at the concentration range from 0.5 up to $125 \mu \mathrm{M}$ without any adverse effect. Taken together, these effects of UA, $p$-CA, and GA may be partly associated with the neuroprotective effect of CF. Furthermore, our findings might raise a possibility of therapeutic applications of $\mathrm{CF}$ for preventing and/or treating neurodegenerative diseases.
\end{abstract}


Keywords: Alzheimer's disease (AD); amyloid $\beta$ peptide (A $\beta)$; Corni fructus; apoptosis; anti-oxidant; neuroprotection

\section{Introduction}

Alzheimer's disease (AD) is a neurodegenerative disorder clinically characterized by progressive loss of memory and impairments in language and behavior [1]. The major neuropathological features in $\mathrm{AD}$ include neurofibrillary tangles and extracellular deposition of $\beta$-amyloid peptide (A $\beta$ ) [2]. The A $\beta$ peptide is derived from amyloid precursor peptide (APP) though $\alpha$-, $\beta$ - and $\gamma$-secretase. The deposition of insoluble $\mathrm{A} \beta$ produces the aggregation of the peptide-forming amyloid fibrils that have been reported to be neurotoxic in vitro and in vivo [3]. Although the mechanisms of neuronal cell death in $\mathrm{AD}$ have not been fully elucidated, neurotoxicity exerted by $\mathrm{A} \beta$ may involve several mechanisms such as ROS generation, increase of intracellular $\mathrm{Ca}^{2+}$, and inflammation [4,5]. Many studies have confirmed that oxidative stress is involved in $\mathrm{AD}$ and the excessive production of $\mathrm{A} \beta$ itself leads to $\mathrm{A} \beta$-induced free radical generation which leads to cell death [6].

Antioxidants have shown to be effective in preventing neurodegenerative disorders including $\mathrm{A} \beta$-induced neurotoxicity [7,8]. Much attention has been paid on natural antioxidants with radical scavenging effect against oxidative damage such as resveratrol and tea catechins [9,10]. Therefore, searching for the compound attenuating oxidative stress might provide a therapeutic strategy to prevent and/or treat $\mathrm{A} \beta$-induced neurotoxicity.

Corni fructus (CF) is the fruit of Cornus officinalis Sieb. et Zucc (Cornaceae). The fruit is considered one of the 25 plant-based drugs most frequently used in Eastern Asian countries such as China, Japan, and Korea. CF possesses antioxidative, antidiabetes, and antineoplastic effects [11-13]. It also has other effects such as anti-inflammation, hepatoprotection and etc. [14]. However, in spite of its diverse biological activities, the neuroprotective effects of $C F$ have not been studied yet.

The EtOAc fraction of $\mathrm{CF}$ ethanol extract exhibited strong protective effect against $\mathrm{A} \beta(25-35)$ induced injury in PC12 cells and three key compounds, ursolic acid (UA), $p$-coumaric acid ( $p$-CA) and gallic acid (GA) were isolated in pure form by the activity-guided isolation in our previous study and identified [15]. Therefore, the aim of the present study was to investigate the neuroprotective properties of the key compounds isolated from $C F$ against $A \beta(25-35)$-induced injury.

\section{Results and Discussion}

\subsection{Ursolic Acid, p-Coumaric Acid and Gallic Acid Protected PC12 Cells against Aß(25-35)-Induced Cytotoxicity}

The chemical structures of UA, $p$-CA, and GA are presented in Figure 1. To assess A $\beta(25-35)$ induced neuronal cell death, the MTT reduction assay was performed. The concentration of $50 \mu \mathrm{M}$ was used for determining $A \beta(25-35)$-induced cellular damage based on our previous results [16]. As shown in Figure 2, PC12 cells treated for $24 \mathrm{~h}$ with $50 \mu \mathrm{M} A \beta(25-35)$ had cell viability reduction of $66.55 \pm 2.84 \%$ compared to the control $(p<0.001)$. UA showed the strongest inhibitory activity 
against $\mathrm{A} \beta(25-35)$-induced cell death followed by GA and $p$-CA at 0.5 and $5 \mu \mathrm{M}$. However, treatment of UA at 50 and $125 \mu \mathrm{M}$ showed somewhat adverse effects on neuronal cell viability. To investigate whether UA itself had toxicity or not, PC12 cells were exposed to 50 and $125 \mu \mathrm{M}$ UA without $50 \mu \mathrm{M}$ $\mathrm{A} \beta(25-35)$ treatment. The result showed that the viability of UA-treated PC12 cells at 50 and $125 \mu \mathrm{M}$ decreased in comparison to the control group but UA exerted neither protection nor exacerbation against $50 \mu \mathrm{M} \mathrm{A} \beta(25-35)$-induced neurotoxicity at the concentrations of 50 and $125 \mu \mathrm{M}$ (Figure $2 \mathrm{~A}$ ). Pretreatment of the cells with $p$-CA also reduced the neuronal cell death caused by $\mathrm{A} \beta$ in concentration-dependent manner (Figure 2B). Particularly, $p$-CA at the concentration of $125 \mu \mathrm{M}$ $(98.89 \pm 7.61 \%, p<0.001)$ showed almost complete inhibition of the $\mathrm{A} \beta(25-35)$-induced cell death. Moreover, the potency of $250 \mu \mathrm{M} p$-CA $(112.50 \pm 4.72 \%)$ was similar to that of $50 \mu \mathrm{M}$ resveratrol $(113.63 \pm 7.57 \%)$ without significant difference $(p<0.001$, data not shown). Here, we compared the key compounds from CF with resveratrol, a potent anti-dementia agent in terms of neuroprotective actions. Among these key compounds, only $p$-CA alone did not affect cell viability even at the higher concentration $(>125 \mu \mathrm{M})$ (data not shown).

Figure 1. The chemical structures of the key compounds isolated from ethyl acetate fraction of Corni fructus.

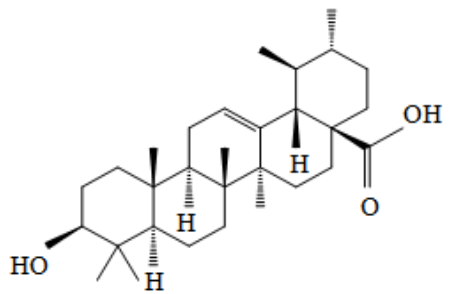

Ursolic acid

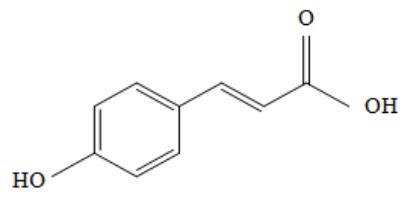

$p$-Coumaric acid

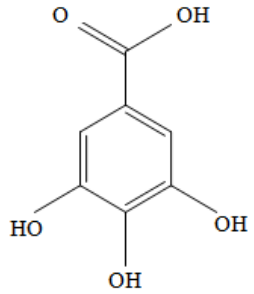

Gallic acid

Figure 2. Protective effects of key compounds isolated from Corni fructus on A $\beta(25-35)$ induced cell death. PC12 cells were pretreated with (A) UA, (B) $p$-CA, and (C) GA for $1 \mathrm{~h}$ and further treated with $50 \mu \mathrm{M}$ of $\mathrm{A} \beta(25-35)$ for $24 \mathrm{~h}$. Cell viability was assessed by measuring MTT reduction. ${ }^{\# \#} p<0.001$ and ${ }^{\# \#} p<0.01$ versus control group. $* * * p<0.001$ and $* * p<0.01$ versus the group treated with $\mathrm{A} \beta(25-35)$ alone.

(A) Ursolic acid (UA)

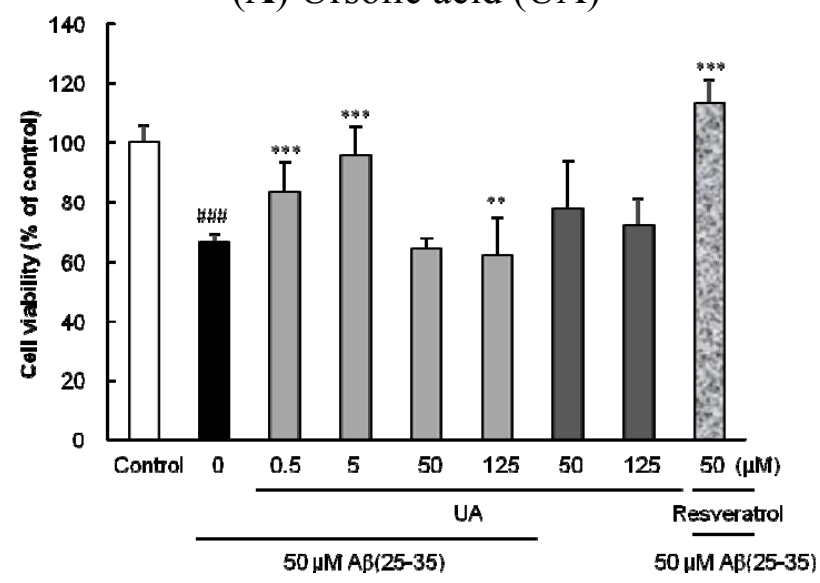


Figure 2. Cont.

(B) $p$-Coumaric acid ( $p$-CA)

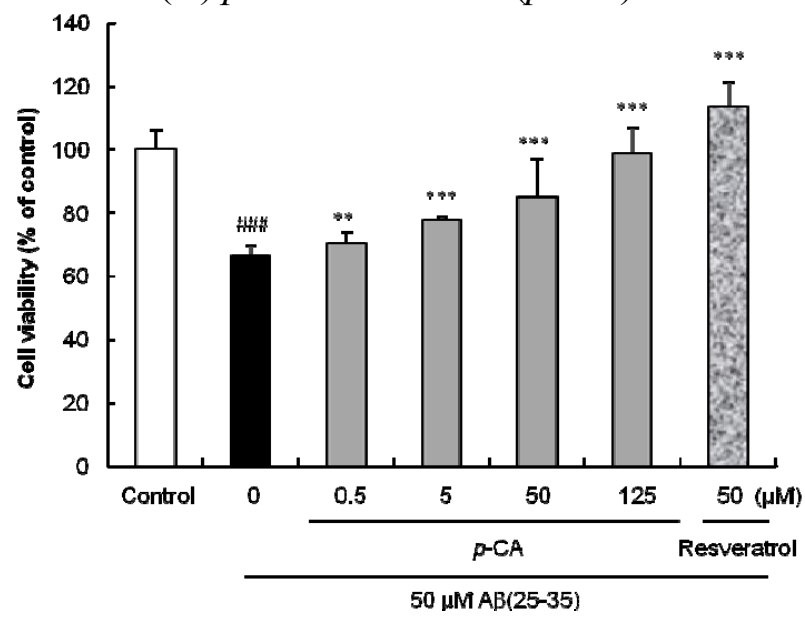

(C) Gallic acid (GA)

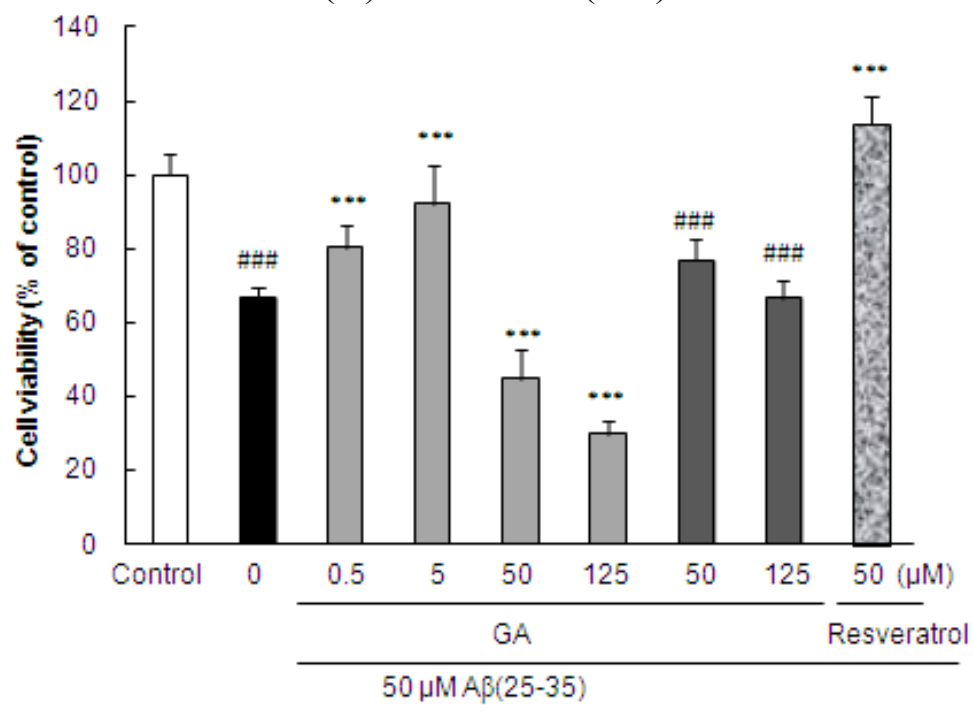

GA also was found to possess similar effect as UA on neuronal cell survival at the concentrations higher than $50 \mu \mathrm{M}$. High concentration of GA itself $(>50 \mu \mathrm{M})$ exerted neuronal cell death showed $19.81 \pm 0.84 \%$ of MTT reduction rate (Figure 2C). Similar result was found in the study of Ban et al. [17]. However, low concentrations ( 0.5 and $5 \mu \mathrm{M})$ of UA and GA did not affect cell viability (data not shown).

\subsection{Ursolic Acid, p-Coumaric Acid and Gallic acid Protected PC12 Cells against Aß(25-35)-Induced} Intracellular ROS Accumulation in PC12 Cells

To determine whether the compounds from CF attenuate cell death by blocking ROS generation or not, the intracellular ROS concentration was measured using the $\mathrm{CM}-\mathrm{H}_{2}$ DCFDA fluorescence dye. In previous MTT reduction experiment, we have demonstrated that UA and GA had adverse effect on cell viability at the concentration over $50 \mu \mathrm{M}$. Therefore, for further experiments, the experimental concentration ranges of UA and GA were adjusted from 0.5 to $5 \mu \mathrm{M}$ that didn't affect cell viability.

Exposure of PC12 cells treated with $\mathrm{A} \beta(25-35)$ resulted in a significant increase of ROS levels $(72.41 \pm 1.81 \%$ vs. $100 \pm 3.83 \%, \mathrm{~A} \beta(25-35)$ vs. control, $p<0.001$, Figure 3$)$. However, treatment of 
cells with the isolated compounds before exposure to $A \beta(25-35)$ appreciably inhibited the ROS generation in dose-dependent manner. At the concentration of $0.5 \mu \mathrm{M}, \mathrm{UA}, p$-CA, and GA significantly reduced $A \beta(25-35)$-induced ROS generation $(51.69 \pm 2.88 \%, 68.86 \pm 9.69 \%$, and $73.00 \pm 13.05 \%$, respectively, $p<0.001)$. In particular, UA showed the strongest inhibitory activity on the $\mathrm{A} \beta(25-35)$-induced ROS accumulation followed by GA and $p$-CA at the low concentrations $(0.5$ and $5 \mu \mathrm{M})$. Furthermore, UA possessed similar ROS protective effect with resveratrol without significant difference $(p<0.001)$. Moreover, the inhibitory effect of 50, $125 \mu \mathrm{M} p$-CA $(45.35 \pm 10.48 \%$ and $41.11 \pm 1.58 \%$, respectively), and $5 \mu \mathrm{M} \mathrm{GA}(42.95 \pm 3.64 \%)$ were similar to that of $50 \mu \mathrm{M}$ resveratrol $(35.31 \pm 4.30 \%)$ without significant difference. UA, $p$-CA, and GA did not show direct reaction with $\mathrm{CM}-\mathrm{H}_{2}$ DCFDA to generate fluorescence (data not shown).

Figure 3. Inhibitory effects of key compounds isolated from Corni fructus on A $\beta(25-35)$ induced intracellular ROS accumulation. PC12 cells were pretreated with (A) UA, (B) $p$-CA, and (C) GA for $1 \mathrm{~h}$ and further treated with $50 \mu \mathrm{M}$ of $\mathrm{A} \beta(25-35)$ for $24 \mathrm{~h}$. ROS production was measured using the $\mathrm{CM}-\mathrm{H}_{2}$ DCFDA fluorescent dye. ${ }^{\# \#} p<0.001$ versus control group. ${ }^{* * *} p<0.001$ versus the group treated with $\mathrm{A} \beta(25-35)$ alone. $\$ \$$, not significantly different.

(A) Ursolic acid (UA)

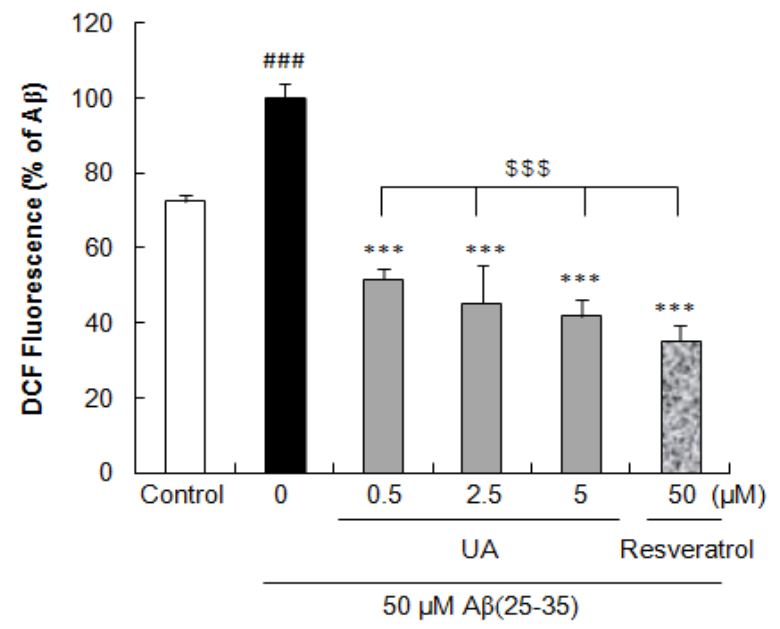

(B) $p$-Coumaric acid ( $p$-CA)

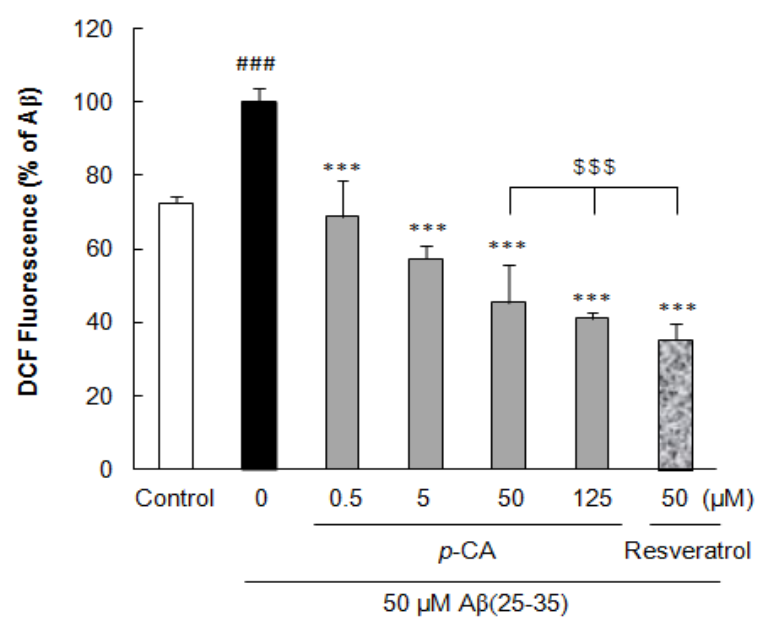

(C) Gallic acid (GA)

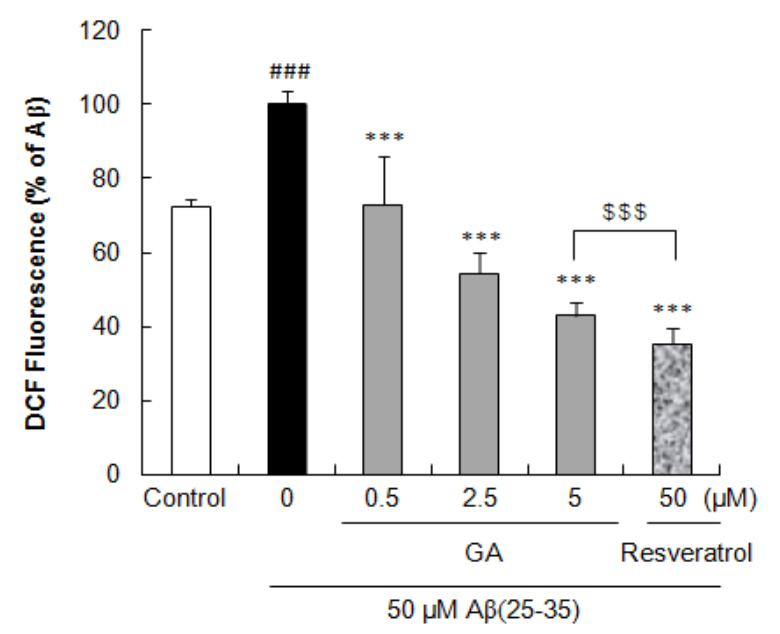


Abnormal production of $A \beta$ is a primary event in the pathological cascade of AD [18]. Several experimental studies suggest an association between $A \beta$, oxidative stress and apoptosis with AD $[19,20]$. ROS produced in mitochondria may leak to the cytoplasm, leading to oxidative stress and the initiation of apoptosis [21,22] Several antioxidants have been demonstrated to be useful for attenuation of $\mathrm{AD}$ development [23-25].

Oxidative damage occurs when ROS are overproduced and exceeds the capacity of the endogenous antioxidant defense systems [26]. Several lines of evidence support the involvement of oxidative stress as an active factor in $A \beta$-mediated neuropathology, by facilitating neurodegeneration though a wide range of molecular events that disturb neuronal homeostasis [27]. Here, we found that UA, $p$-CA, and GA strongly suppressed the accumulation of intracellular ROS in PC12 cells. The result have confirmed that $\mathrm{A} \beta(25-35)$-induced $\mathrm{PC} 12$ cells produce ROS and can be protected from A $\beta$ toxicity by antioxidant such as UA, $p$-CA, and GA. From our results, it can be explained that cytoprotective effects of UA, $p$-CA, and GA may be attributed, at least in part, to their antioxidant properties.

\subsection{Ursolic Acid, p-Coumaric Acid and Gallic Acid Protected PC12 Cells against AB(25-35)-Induced} Apoptosis

The cells stained with Hoechst 33342 revealed marked chomatin condensation and apoptotic body formation when examined by a fluorescence microscope. In contrast to round and blue nuclei observed in viable PC12 cells of control group (Figures 4Aa, 5Aa, and 6Aa), several marked characteristics of apoptosis such as chromatin condensation and nuclear fragmentation were observed in cells exposed to $50 \mu \mathrm{M} \mathrm{A} \beta(25-35)$ for $24 \mathrm{~h}$ (Figures $4 \mathrm{Ab}, 5 \mathrm{Ab}$, and 6Ab). These characteristic changes in cellular morphology were significantly reduced in the cells pretreated with the compounds (Figures 4-6). Especially, the preincubation with $125 \mu \mathrm{M} p$-CA almost completely blocked the apoptosis in terms of the morphological appearance of PC12 cells (Figure 5Af).

The proportion of apoptotic neurons was calculated in Figures $4 \mathrm{~B}, 5 \mathrm{~B}$, and $6 \mathrm{~B}$. In comparison to only $9.72 \pm 0.70 \%$ apoptotic cells in total population of PC12 cells in control group, exposure to $50 \mu \mathrm{M} \mathrm{A} \beta(25-35)$ alone produced $37.81 \pm 1.82 \%$ apoptosis. However, pre-incubation with 0.5 and $5 \mu \mathrm{M}$ of UA or GA significantly decreased the $\mathrm{A} \beta(25-35)$-induced apoptosis. Moreover, the addition of $p$-CA significantly decreased $\mathrm{A} \beta(25-35)$-induced apoptotic cell death showing $35.10 \pm 0.81 \%$, $32.27 \pm 0.76 \%$, and $27.94 \pm 1.61 \%$ at the concentration of $0.5,5$, and $50 \mu \mathrm{M}$. In particular, $p$-CA at the concentration of $125 \mu \mathrm{M}(10.65 \pm 0.36 \%, p<0.001)$ showed almost complete inhibition of the $\mathrm{A} \beta(25-35)$-induced apoptosis. The neuroprotective effects of isolated compounds from CF against cellular apoptosis displayed dose-dependent pattern.

Several investigators have demonstrated that the neurotoxicity of $\mathrm{A} \beta$ can be mediated by ROS, which may contribute to the increased evidence of apoptosis found in $\mathrm{AD}[28,29]$. A $\beta$-induced ROS accumulation cause damage to neuronal membrane lipids, proteins, and nucleic acids, and ultimately leads to apoptosis which is believed to play a critical role in cell loss during progression of $\mathrm{AD}[30,31]$. Some of the classical features of $\mathrm{A} \beta$-induced apoptosis such as decreased cell viability, DNA condensation, and DNA fragmentation were detected in PC12 cells in this study. 
Figure 4. Inhibitory effects of ursolic acid isolated from Corni fructus on A $\beta(25-35)$ induced apoptosis. (A) PC12 cells were pretreated with UA for $1 \mathrm{~h}$ and further treated with $50 \mu \mathrm{M}$ of $\mathrm{A} \beta(25-35)$ for $24 \mathrm{~h}$. Morphological apoptosis was determined by Hoechst 33342 staining under fluorescence microscopy (magnification $\times 400$ ). (a) Control; (b) $50 \mu \mathrm{M}$ $\mathrm{A} \beta(25-35)$; (c) $50 \mu \mathrm{M} \mathrm{A} \beta(25-35)+0.5 \mu \mathrm{M} \mathrm{UA}$; (d) $50 \mu \mathrm{M} \mathrm{A} \beta(25-35)+5 \mu \mathrm{M}$ UA. (B) Histogram showing the percentage of apoptotic cells in total cell population after different treatments. ${ }^{\# \#} p<0.001$ versus normal group. ${ }^{* *} p<0.01$ versus the group treated with $\mathrm{A} \beta(25-35)$ alone. Data represent the mean \pm SD of three independent experiments.

(A)
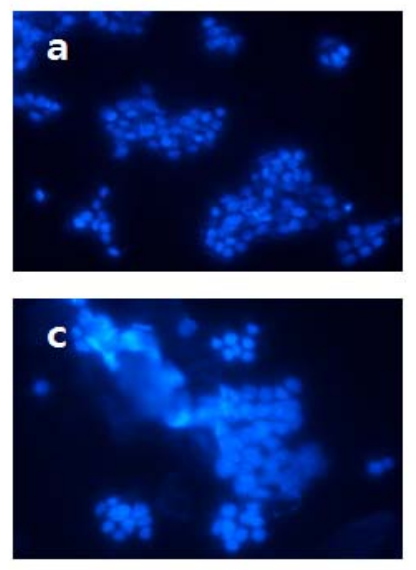
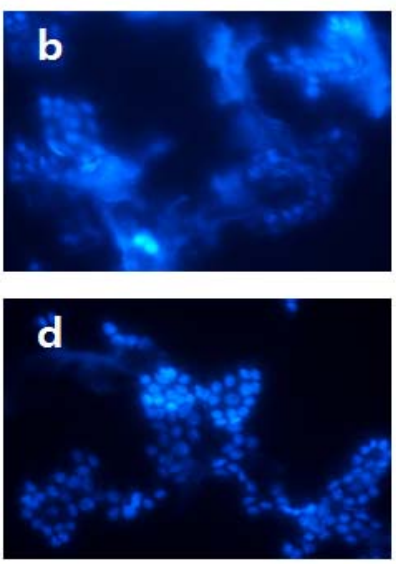

(B)

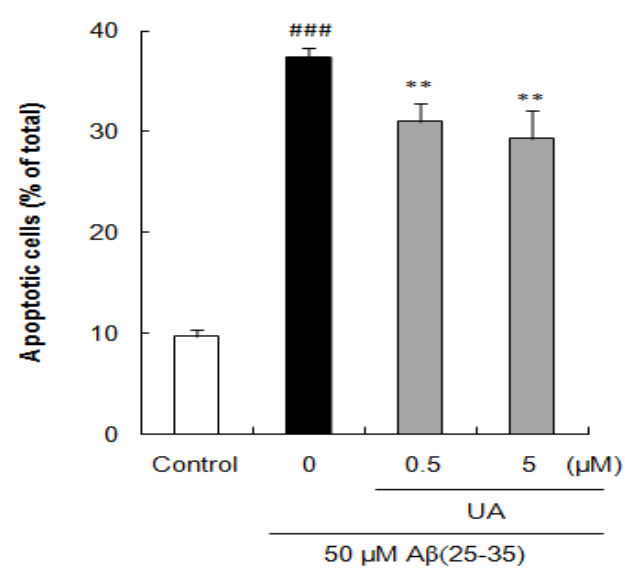

Figure 5. Inhibitory effects of $p$-coumaric acid isolated from Corni fructus on $\mathrm{A} \beta(25-35)$ induced apoptosis. (A) PC12 cells were pretreated with $p$-CA for $1 \mathrm{~h}$ and further treated with $50 \mu \mathrm{M}$ of $\mathrm{A} \beta(25-35)$ for $24 \mathrm{~h}$. Morphological apoptosis was determined by Hoechst 33342 staining under fluorescence microscopy (magnification $\times 400$ ). (a) Control; (b) $50 \mu \mathrm{M}$ $\mathrm{A} \beta(25-35)$; (c) $50 \mu \mathrm{M} \mathrm{A} \beta(25-35)+0.5 \mu \mathrm{M} p$-CA; (d) $50 \mu \mathrm{M} \mathrm{A} \beta(25-35)+5 \mu \mathrm{M} p$-CA; (e) $50 \mu \mathrm{M} \mathrm{A} \beta(25-35)+50 \mu \mathrm{M} p$-CA, (f) $50 \mu \mathrm{M} A \beta(25-35)+125 \mu \mathrm{M} p$-CA. (B) Histogram showing the percentage of apoptotic cells in total cell population after different treatments. ${ }^{\# \#} p<0.001$ versus normal group. $* * * p<0.001$ versus the group treated with $\mathrm{A} \beta(25-35)$ alone. Data represent the mean $\pm \mathrm{SD}$ of three independent experiments.

(A)
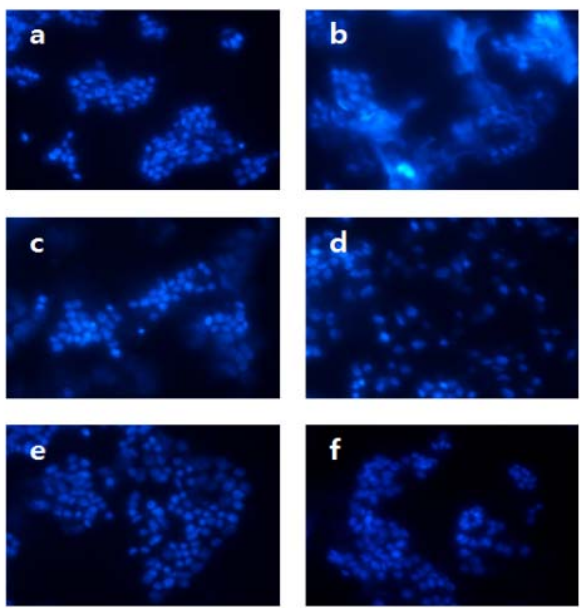

f

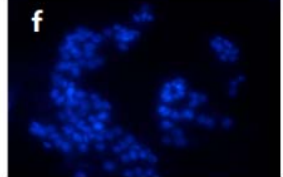

(B)

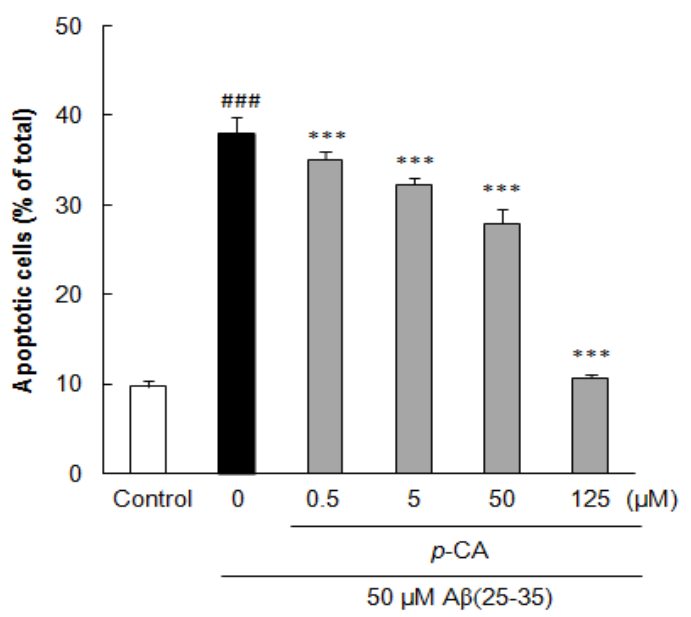


Figure 6. Inhibitory effects of gallic acid isolated from Corni fructus on A $\beta(25-35)$ induced apoptosis. (A) PC12 cells were pretreated with GA for $1 \mathrm{~h}$ and further treated with $50 \mu \mathrm{M}$ of $\mathrm{A} \beta(25-35)$ for $24 \mathrm{~h}$. Morphological apoptosis was determined by Hoechst 33342 staining under fluorescence microscopy (magnification $\times 400$ ). (a) Control; (b) $50 \mu \mathrm{M}$ $\mathrm{A} \beta(25-35)$; (c) $50 \mu \mathrm{M} \mathrm{A} \beta(25-35)+0.5 \mu \mathrm{M}$ GA; (d) $50 \mu \mathrm{M} \mathrm{A} \beta(25-35)+5 \mu \mathrm{M}$ GA. (B) Histogram showing the percentage of apoptotic cells in total cell population after different treatments. ${ }^{\# \#} p<0.001$ versus normal group. $* * * p<0.001$ versus the group treated with $\mathrm{A} \beta(25-35)$ alone. Data represent the mean $\pm \mathrm{SD}$ of three independent experiments.

(A)
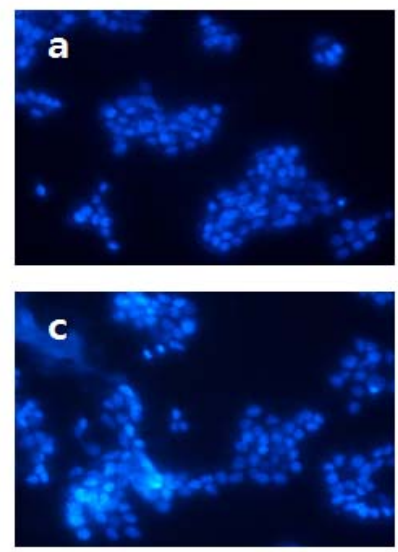
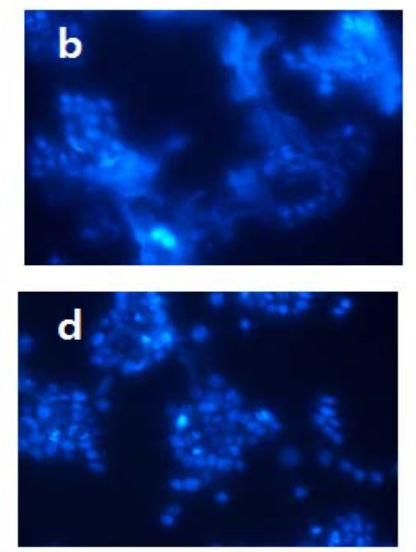

(B)

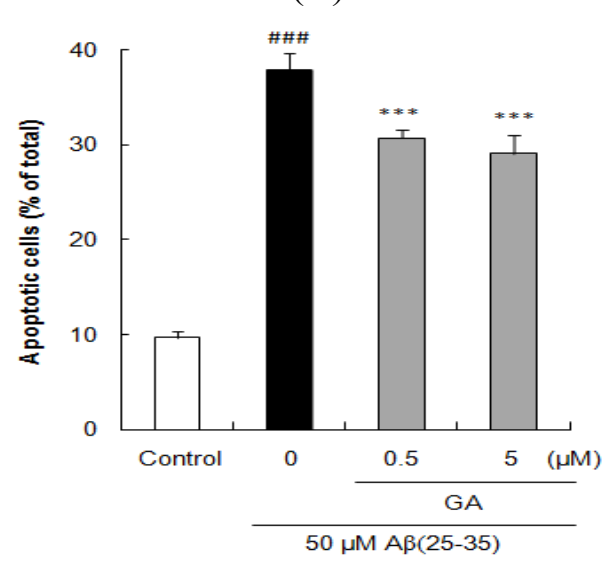

\subsection{Ursolic Acid, p-Coumaric Acid and Gallic Acid Inhibited Aß(25-35)-Induced Caspase-3 Activity}

The activation of caspase-3, a family of cysteine proteases, is believed to be an important factor for apoptosis [31]. To examine whether the isolated compounds modulates the proteolytic activity of caspase-3, we measured the caspase-3-like protease activity using the substrate DEVD- $p$ NA. As shown in Figure 7, the enzyme activity of caspase-3 was significantly elevated in A $\beta(25-35)$-treated PC12 cells (1.52 fold, $p<0.05)$.

Figure 7. Protective effects of $p$-coumaric acid isolated from Corni fructus on $\mathrm{A} \beta(25-35)$ induced caspase-3 activation. PC12 cells were pretreated with $p$-CA for $1 \mathrm{~h}$ and further treated with $50 \mu \mathrm{M}$ of $\mathrm{A} \beta(25-35)$ for $24 \mathrm{~h}$. Caspase-3 activity was measured with the colorimetric caspase-3 assay kit. ${ }^{\#} p<0.05$ versus normal group. ${ }^{* * *} p<0.001$ versus the group treated with $A \beta(25-35)$ alone.

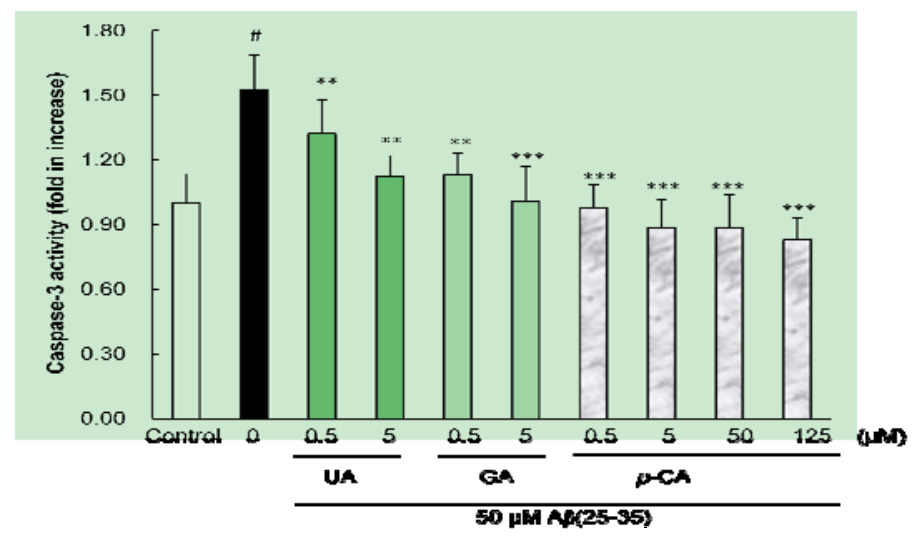


However, preincubation with UA and GA for $1 \mathrm{~h}$ attenuated A $\beta(25-35)$-induced caspase-3 activation. Among the three isolated compounds, $p$-CA exhibited the strongest inhibitory effect on caspase- 3 activity even at the concentration of $0.5 \mu \mathrm{M}$.

Apoptosis is associated with the activation of a family of aspartic acid-specific cysteine proteases [32,33]. The present study demonstrated that $\mathrm{A} \beta$ induces the apoptotic death of PC12 cells, as judged by morphological nuclear changes, DNA fragmentation, and cell blebbing. These apoptotic features were attenuated by addition of UA, $p$-CA, and GA, suggest that these compounds exert protective effects against $A \beta$-induced cell death by affecting partly by attenuating caspase- 3 activity. In protecting cells against $\mathrm{A} \beta$-induced apoptosis, UA and GA showed similar potency, while $p$-CA was stronger than UA and GA. Furthermore, in the present study, it was shown that $p$-CA can inhibit caspase- 3 activity in $\mathrm{A} \beta$ (25-35)-treated PC12 cells, suggesting that $p$-CA could exert a protective role at the execution phase of apoptosis. Furthermore, these results suggest a special link between ROS and apoptosis, and the protective effect of UA, $p$-CA and GA on apoptosis is due, at least in part, to its antioxidant property.

The key compounds isolated from CF have the specific characteristics. UA, a natural pentacyclic triterpenoid carboxylic acid, is the major component of some traditional medicinal herbs and is well known to possess a wide range of biological functions, such as antioxidative, anti-inflammation and anticancer activities, that are able to counteract endogenous and exogenous biological stimuli [34,35]. A study on mechanism revealed that UA blocked the cell cycle progression in the G1 phase and that UA treatment resulted in the triggering of apoptosis as determined by a DNA fragmentation assay [36].

$p$-CA found in fruits and vegetables is an intermediate product of the phenylpropanoid pathway in plants. Previous investigators have shown that $p$-coumaric acid exhibited antioxidant and anti-inflammatory properties [37,38]. Moreover, maltolyl $p$-coumarate, a $p$-CA derivative, is a potentially effective candidate against $\mathrm{AD}$ [39]. The ethylenic group between a phenyl ring carrying a $p$-hydroxyl group and the carboxylate group has a highly favorable effect on the reducing properties of the $\mathrm{OH}$ group [40,41]. Moreover, the presence of the $-\mathrm{CH}=\mathrm{CH}-\mathrm{COOH}$ groups in $p$-CA ensures greater subsequent radical stabilization [40]. Therefore, $p$-CA is very important for antioxidant activity, which can be boosted by the electron-donating substituent, the $-\mathrm{CH}=\mathrm{CH}-\mathrm{COOH}$, which leads $p$ - $\mathrm{CA}$ to be beneficial inhibitors of ROS accumulation and cell protection.

GA, a strong natural antioxidant, is widespread in tea and wine and has been proven to be one of the anticarcinogenic polyphenols present in green tea [42]. Due to this antioxidant effect, GA containing plant extracts have showed antidiabetic, antiangiogenic, and antimelanogenic effects and reduced oxidative liver and kidney damage [17]. From its unique structure, GA is possible to obtain two radicals by abstraction of a hydrogen atom from the 3-OH $(5-\mathrm{OH})$ and 4-OH groups [43]. Overall, the resulting effect of key compounds with the characteristics such as the structure-activity relationships and other abilities may help to elucidate this issue or even to discover new neuroprotective agents in further studies.

Exposure to $\mathrm{A} \beta$ leads to the accumulation of ROS, leading to subsequent caspase- 3 activation, cell apoptosis and neuronal cell death. In the present study, we have shown that UA, $p$-CA, and GA isolated from CF not only decreased $A \beta(25-35)$-induced ROS overproduction and caspase-3 activity, but also attenuated apoptosis and cell death in PC12 cells. The results suggest that these compounds are novel and effective neuroprotective agents against oxidative damage in $A \beta(25-35)$-induced 
toxicity. In protecting cells against $\mathrm{A} \beta$ neurotoxicity, UA and GA have stronger ability against ROS generation than $p$-CA, while $p$-CA showed the strongest anti-apoptotic activity among the key compounds isolated from CF. Particularly, $p$-CA also protects PC12 cells up to $125 \mu \mathrm{M}$ concentration, the higher concentration that we utilized without any cytotoxicity. Further, exploration of UA, $p$-CA, and GA antioxidant properties may provide opportunities for novel pharmacological interventions aiming at preventing and/or palliating the consequences of $\mathrm{AD}$.

\section{Experimental}

\subsection{General}

$\beta$-Amyloid [A $\beta(25-35)], 3,5,4$ '-trihydroxy-trans-stilbene (resveratrol), and 3-[4,5-dimethylthiazol2-yl]-2,5-diphenyltetrazolium bromide (MTT) were purchased from Sigma Chemical Co. (St. Louis, MO, USA). RPMI 1640 medium, phosphate buffered saline (PBS), trypsin $0.25 \%$ solution, and penicillin/streptomycin solution were obtained from Hyclone Laboratories, Inc. (Logan, UT, USA). Fetal bovine serum was obtained by PAA Laboratories GmbH. (Linz, Austria). N2 supplement and RPMI 1640 phenol red free medium were purchased from Gibco BRL (Grand Island, NY, USA). 5-[and-6]-Chloromethyl-2',7'-dichlorodihydrofluorescein diacetate, acetyl ester (CM-H ${ }_{2}$ DCFDA) and Hoechst 33342 dye were obtained from Molecular Probes Inc. (Eugene, OR, USA). Dimethylsulfoxide (DMSO) was supplied from Bio Basic Inc. (Ontario, Canada). All other chemicals used were of the highest grade commercially available. $A \beta(25-35)$, which is the most toxic peptide fragment derived from APP, was dissolved in DMSO at a concentration of $10 \mathrm{mM}$ and stored at $-20{ }^{\circ} \mathrm{C}$. The stock solution was diluted with PBS to appropriate concentration and incubated for $48 \mathrm{~h}$ at $37^{\circ} \mathrm{C}$ for aggregation prior to each experiment [16]. Samples were dissolved in DMSO and further diluted with sterilized water. The final concentration of DMSO was less than $0.01 \%$, which did not affect cell viability.

\subsection{Plant Material, Extraction, Fractionation, and Isolation of Key Compounds from Corni fructus}

CF was purchased from agricultural farm in Gurye, Jeonnam, Korea in Nov. 2007. The voucher specimen (No. NFF 0407-002) has been deposited at Nutraceuticals and Functional Food Lab., Dong-A University, Busan, Korea and the whole plant extract was prepared as published earlier [15]. In brief, the dried CF $(3 \mathrm{~kg})$ was refluxed with $95 \%$ ethanol $(11 \mathrm{~L} \times 3)$ and its extract was evaporated to dryness. The ethanol extract $(1.15 \mathrm{~kg})$ was suspended in water, and partitioned successively with $n$-hexane, dichloromethane (MC), ethyl acetate (EtOAc), and $n$-butanol $(\mathrm{BuOH})$ to give fractions of n-hexane (23 g), MC (89 g), EtOAc (110 g), and BuOH (253 g), respectively, and a water layer (680 g).

The EtOAc soluble fraction, which exhibited the most potent neuroprotective effect against $\mathrm{A} \beta$ (25-35)-induced neurotoxicity among the other organic solvent fractions, was applied onto silica gel (70-230 mesh Merck, Darmstadt, Germany) open column chomatography and five fractions including compound CO-1 (20.3 mg) were obtained. The experiment of the activity-guided separation of fractions on neuroprotective effect against $A \beta(25-35)$-induced cell death showed that fraction 2 was more potent than others (data not shown), and so fraction $2(565.5 \mathrm{mg}$ ) was separated by re-chomatography on a silica gel column with a n-hexane:EtOAc:MeOH step-gradient 
$(20: 10: 1 \rightarrow 10: 10: 1 \rightarrow 5: 10: 1 \rightarrow 0: 0: 1)$ to yield compound CO-1 (3.1 mg), CO-2 (10.7 mg) and compound CO-3 (16.6 mg) and the chemical structure of the isolated compounds were identified as ursolic acid, $p$-coumaric acid, and gallic acid (Figure 1), respectively, in our previous study [15].

\subsection{Cell Culture}

Rat PC12 cell line, which has been used for neurological experiment, was obtained from the American Type Cell Collection (ATCC) and were maintained in RPMI 1640 medium supplemented with $10 \%$ donor equine serum, $5 \%$ fetal bovine serum, and $100 \mathrm{U} / \mathrm{mL}$ penicillin and $100 \mu \mathrm{g} / \mathrm{mL}$ streptomycin at $37{ }^{\circ} \mathrm{C}$ in a humidified $95 \%$ air $/ 5 \% \mathrm{CO}_{2}$ incubator. All cells were cultured in collagen-coated culture dishes. The medium was changed every other day, and cells were plated at an appropriate density according to each experimental scale. After $24 \mathrm{~h}$ subculture, cells were switched to serum-free $\mathrm{N} 2$ defined medium for treatment.

\subsection{Cell Viability Assay}

Cell viability was assessed by measuring formazan produced by the reduction of MTT. The MTT assay is a sensitive measurement of the normal metabolic status of cells, particularly those of mitochondria, which reflects early cellular redox changes. Therefore, the amount of formazan produced is proportional to the number of viable cells. Briefly, the cells were plated in 96 well culture plates at the density of $1 \times 10^{4}$ cells/well and allowed to adhere at $37^{\circ} \mathrm{C}$ for $24 \mathrm{~h}$. After incubation with various concentration of sample solution for $1 \mathrm{~h}$, the cells were treated with $50 \mu \mathrm{M} A \beta(25-35)$ for $24 \mathrm{~h}$. Thereafter, MTT reagent (final concentration, $0.5 \mathrm{mg} / \mathrm{mL}$ ) was added to each of the wells and the plate was incubated for an additional about $3 \mathrm{~h}$ at $37{ }^{\circ} \mathrm{C}$. At the end of the incubated period, the medium with MTT was removed and $100 \mu \mathrm{L}$ DMSO was added to each well. The formazan reduction product was measured by reading absorbance at $570 \mathrm{~nm}$ in a microplate reader (ELX808, Biotek, Winooski, VT, USA). Cell viability was expressed as a percentage of the control culture.

\subsection{Intracellular Reactive Oxygen Species Production Determination}

Intracellular ROS was monitored by using the fluorescent probe 5-[and-6]-chloromethyl-2',7'dichlorodihydrofluorescein diacetate (CM- $\mathrm{H}_{2}$ DCFDA), which is intracellular oxidized to the fluorescent 2',7'-dichlorofluorescein (DCF) in the presence of cellular peroxides [44]. Briefly, PC12 cells were seeded at a density of $1 \times 10^{4}$ cells/well into 96 well plates and allowed to grow at $37{ }^{\circ} \mathrm{C}$ for $24 \mathrm{~h}$. After treatment with $50 \mu \mathrm{M} \mathrm{A} \beta(25-35)$ for $24 \mathrm{~h}$ in the presence or absence of sample solution, the serum-free $\mathrm{N} 2$ defined medium was switched to HBSS with $10 \mu \mathrm{M} \mathrm{CM}-\mathrm{H}_{2} \mathrm{DCFDA}$ at $37{ }^{\circ} \mathrm{C}$ for $30 \mathrm{~min}$. Then, the medium was removed and $100 \mu \mathrm{L}$ HBSS was added to each well. Fluorescence intensity was measured at an excitation wavelength of $485 \mathrm{~nm}$ and an emission wavelength of $528 \mathrm{~nm}$ using a fluorescence spectrophotometer (FLX800, Biotek). Data were given as percents relative to the oxidative stress of the group treated with $\mathrm{A} \beta(25-35)$ alone set to $100 \%$. 


\subsection{Apoptotic Morphology Observation by Hoechst 33342 Staining}

Chomosomal condensation and morphological changes in the nucleus were observed by using the chomatin dye, Hoechst 33342 [23]. Cells with homogeneously stained nuclei were considered to be viable. On the other hand, chomatin condensation and/or fragmentation were the characteristic indicative of apoptosis. Briefly, PC12 cells $\left(1 \times 10^{6}\right)$ cultured on cover slips were plated in 6 well plates with $2 \mathrm{~mL}$ of medium in every well, and exposed to $50 \mu \mathrm{M} A \beta(25-35)$ with various concentrations of sample solution for $24 \mathrm{~h}$. After treatments, the cells were fixed with $4 \%$ formaldehyde in PBS for $20 \mathrm{~min}$ at RT and stained with $1 \mu \mathrm{g} / \mathrm{mL}$ Hoechst 33342 for $20 \mathrm{~min}$ at RT and Hoechst-stained cells were visualized and photographed under a fluorescent microscope (Olympus, Tokyo, Japan). To quantify the apoptotic process, neurons with fragmented or condensed DNA and normal DNA were counted. Data was shown as apoptotic cells as a percentage of total cells.

\subsection{Measurement of Caspase-3 Activity}

The extent of caspase- 3 activation in PC12 cells treated with $\mathrm{A} \beta(25-35)$ was assessed using the commercially available colorimetric assay kit in accordance with the protocol supplied by the manufacturer (BioVision, Mountain View, CA, USA). The assay is based on spectrophotometric detection of the chomophore $p$-nitroanilide ( $p$ NA) after its cleavage by caspase-3 from the labeled substrate, DEVD- $p$ NA. Briefly, cultured PC12 cells $\left(1.5 \times 10^{6}\right)$ were lysed for $10 \mathrm{~min}$ in an ice bath, and the lysates were centrifuged at $10,000 \mathrm{~g}$ at $4{ }^{\circ} \mathrm{C}$ for $5 \mathrm{~min}$. The protein concentrations in the supernatants were determined using the Bradford protein assay kit (Pierce Biotechnology, Rockford, IL, USA). Protein samples were incubated with the substrate peptide $(200 \mu \mathrm{M})$ in $50 \mu \mathrm{L}$ of incubation buffer at $37{ }^{\circ} \mathrm{C}$ for $1 \mathrm{~h}$. Absorbance of the chomophore $p \mathrm{NA}$ produced was measured using a microplate reader at wavelength of $405 \mathrm{~nm}$. Data were expressed as a fold increase in caspase activity of apoptotic cells over that of non induced cells.

\subsection{Statistical Analysis}

All data were expressed as means \pm standard deviation (SD). Statistical differences between groups were performed by analysis of variance (ANOVA) with Duncan's multiple range test using the Statistical Analysis System (SAS). A value of $p<0.05$ was considered statistically significant.

\section{Conclusions}

The results indicate, for the first time, that UA, $p$-CA and GA derived from CF exert a combination of neuroprotective, anti-oxidative and anti-apoptotic effects against $\mathrm{A} \beta(25-35)$ damage. On these grounds, UA, $p$-CA, and GA derived from $\mathrm{CF}$ demonstrated to have neuroprotective effect against $\mathrm{A} \beta(25-35)$-induced neurotoxicity via anti-oxidant and anti-apoptotic property, could be useful as a therapeutic agent for treatment of $A \beta$-induced neuronal degeneration diseases such as AD. 


\section{Acknowledgments}

This research was supported by Basic Science Research Program though the National Research Foundation (NRF) funded by the Ministry of Education, Science and Technology (2009-0075037).

\section{References}

1. Liu, Q.; Kou, J.P.; Yu, B.Y. Ginsenoside Rg1 protects against hydrogen peroxide-induced cell death in PC12 cells via inhibiting NF-kB activation. Neurochem. Int. 2011, 58, 119-125.

2. Xie, X.; Wang, H.T.; Li, C.L.; Gao, X.H.; Ding, J.L.; Zhao, H.H.; Lu, Y.L. Ginsedoside Rb1 protects PC12 cells against $\beta$-amyloid-induced cell injury. Mol. Med. Rep. 2010, 3, 635-639.

3. Li, M.H.; Jang, J.H.; Sun, B.; Surh, Y.J. Protective effects of oligomers of grape seed polyphenols against $\beta$-amyloid-induced oxidative cell death. Ann. NY Acad. Sci. 2004, 1030, 317-329.

4. Gray, C.W.; Patel, A.J. Neurodegeneration mediated by glutamate and $\beta$-amyloid peptide: A comparison and possible interaction. Brain Res. 1995, 691, 169-179.

5. Ueda, K.; Shinohara, S.; Yagami, T.; Asakura, K.; Kawasaki, K. Amyloid $\beta$ protein potentiates $\mathrm{Ca}^{2+}$ influx though L-type voltage-sensitive $\mathrm{Ca}^{2+}$ channels: A possible involvement of free radicals. J. Neurochem. 1997, 68, 265-271.

6. Muthaiyah, B.; Essa, M.M.; Chauhan, V.; Chauhan, A. Protective effects of walnut extract against amyloid beta peptide-induced cell death and oxidative stress in PC12 cells. Neurochem. Res. 2011, 36, 2096-2103.

7. Floyd, R.A. Antioxidants, oxidative stress, and degenerative neurological disorders. Proc. Soc. Exp. Biol. Med. 1999, 222, 236-245.

8. Calabrese, V.; Guagliano, E.; Sapienza, M.; Panebianco, M.; Calafato, S.; Puleo, E.; Pennisi, G.; Mancuso, C.; Allan, B.D.; Stella, A.G. Redox regulation of cellular stress response in aging and neurodegenerative disorders: Role of vitagenes. Neurochem. Res. 2006, 32, 757-773.

9. Ban, J.Y.; Jeon, S.Y.; Nguyen, T.T.H.; Bae, K. Neuroprotective effect of oxyresveratrol from Smilacis Chinae Rhizome of amyloid beta-protein (25-35) induced neurotoxicity in cultured rat cortical neurons. Biol. Pharm. Bull. 2006, 29, 2419-2424.

10. Conte, A.; Pellegrini, S.; Tagliazucchi, D. Synergistic protection of PC12 cells from $\beta$-amyloid toxicity by resveratrol and catechin. Brain Res. Bull. 2003, 62, 29-38.

11. Yokozawa, T.; Yamabe, N.; Kim, H.Y.; Kang, K.S.; Hur, J.M.; Park, C.H.; Tanaka, T. Protective effects of Morroniside isolated from Corni fructus against renal damage in streptozotosin-induced diabetic rats. Biol. Pharm. Bull. 2008, 31, 1422-1428.

12. Sung, Y.H.; Chang, H.K.; Kim, S.E.; Kim, Y.M.; Seo, J.H.; Shin, M.C.; Shin, M.S.; Yi, J.W.; Shin, D.H.; Kim, H.; et al. Anti-inflammatory and analgesic effects of the aqueous extract of Corni fructus in murine RAW 264.7 macrophage cells. J. Med. Food 2009, 12, 788-795.

13. Lee, S.O.; Kim, S.Y.; Han, S.M.; Kim, H.M.; Ham, S.S.; Kang, I.J. Corni fructus scavenges hydroxy radicals and decreases oxidative stress in endothelial cells. J. Med. Food 2006, 9, 594-598.

14. Chang, J.S.; Chiang, L.C.; Hsu, F.F.; Lin, C.C. Chemoprevention against hepatocellular carcinoma of Cornus officinalis in vitro. Am. J. Chin. Med. 2004, 32, 717-725. 
15. Youn, K.; Jun, M. Inhibitory effects of key compounds isolated from Corni fructus on BACE1 activity. Phytother. Res. 2012, doi:10.1002/ptr.4638.

16. Song, K.S.; Jeong, W.S.; Jun, M. Inhibition of $\beta$-Amyloid peptide-induced neurotoxicity by kaempferol-3-O-(6"-acetyl)- $\beta$-glucopyranoside from butterbur leaves in B103 cells. Food Sci. Biotechnol. 2012, 21, 845-852.

17. Ban, J.Y.; Nguyen, H.T.T.; Lee, H.J.; Cho, S.O.; Ju, H.S.; Kim, J.Y.; Bae, K.H.; Song, K.S.; Seong, Y.H. Neuroprotective properties of gallic acid from Sanguisorbae radix on amyloid $\beta$ protein (25-35)-induced toxicity in cultured rat cortical neurons. Biol. Pharm. Bull. 2008, 31, $149-153$.

18. Selkoe, D.J. Cell biology of the amyloid beta-protein precursor and the mechanism of Alzheimer's disease. Annu. Rev. Cell Biol. 1994, 10, 373-403.

19. Cotman, C.W.; Tenner, A.J.; Cummings, B.J. $\beta$-Amyloid converts an acute phase injury response to chonic injury responses. Neurobiol. Aging 1996, 17, 723-731.

20. Kokoszka, J.E.; Coskun, P.; Esposito, L.A.; Wallace, D.C. Increased mitochondrial oxidative stress in the SOD2(+/-) mouse results in the age-related decline of mitochondrial function culminating in increased apoptosis. Proc. Natl. Acad. Sci. USA 2001, 98, 2278-2283.

21. Behl, C.; Davis, J.B.; Lesley, R.; Schubert, D. Hydrogen peroxide mediates amyloid beta protein toxicity. Cell 1994, 77, 817-827.

22. Butterfield, D.A.; Castegna, A.; Lauderback, C.M.; Drake, J. Evidence that amyloid beta-peptideinduced lipid peroxidation in Alzheimer's disease brain contributes to neuronal death. Neurobiol. Aging 2002, 5, 655-664.

23. Lee, H.J.; Yoon, M.Y.; Kim, J.Y.; Kim, Y.S.; Park, H.R.; Park, E.J. Antioxidant activity of Glycyrrhiza uralensis fisch extracts on hydrogen peroxide-induced DNA damage in human leucocytes and cell death in PC12 cells. Food Sci. Biotechnol. 2008, 17, 343-348.

24. Lee, S.M.; Yoon, M.Y.; Park, H.R. Protective effects of Paeonia lactiflora pall on hydrogen peroxide-induced apoptosis in PC12 cells. Biosci. Biotechnol. Biochem. 2008, 72, 1272-1277.

25. Lee, S.Y.; Ha, T.Y.; Son, D.J.; Kim, S.R.; Hong, J.T. Effect of sesaminol glucosides on $\beta$-amyloidinduced PC12 cell death though antioxidant mechanisms. Neurosci. Res. 2005, 52, 330-341.

26. Ge, Y.S.; Teng, W.Y.; Zhang, C.D. Protective effect of cyclophilin A against Alzheimer's amyloid beta-peptide (25-35)-induced oxidative stress in PC12 cells. Chin. Med. J. 2009, 122, 716-724.

27. Peng, Q.L.; Bu'Zard, A.R.; Lau, B.H.S. Pycnogenol protects neurons from amyloid- $\beta$ peptideinduced apoptosis. Mol. Brain Res. 2002, 104, 55-65.

28. Hoi, C.P.; Ho, Y.P.; Baum, L.; Chow, A.H.L. Neuroprotective effect of Honokiol and Magnolol, compounds from Magnolia officinalis, on beta-amyloid-induced toxicity in PC12 cells. Phytother. Res. 2010, 24, 1538-1542.

29. Markesbery, W.R. Oxidative stress hypothesis in Alzheimer's disease. Free Radic. Biol. Med. 1997, 23, 134-147.

30. Jang, M.H.; Piao, X.L.; Kim, H.Y.; Cho, E.J.; Baek, S.H.; Kwon, S.W.; Park, J.H. Resveratrol oilgomers from Vitis amurensis attenuate $\beta$-amyloid-induced oxidative stress in PC12 cells. Biol. Pharm. Bull. 2007, 30, 1130-1134. 
31. Varadarajan, S.; Yatin, S.; Aksenova, M.; Butterfield, D.A. Alzheimer's amyloid $\beta$-peptideassociated free radical oxidative stress and neurotoxicity. J. Struct. Biol. 2000, 130, 184-208.

32. Zhang, H.Y.; Liu, Y.H.; Wang, H.Q.; Xu, J.H.; Hu, H.T. Puerarin protects PC12 cells against $\beta$-amyloid-induced cell injury. Cell Biol. Int. 2008, 32, 1230-1237.

33. Fukui, K.; Takatsu, H.; Shinkai, T.; Suzuki, S.; Abe, K.; Urano, S. Appearance of amyloid beta-like substances and delayed-type apoptosis in rat hippocampus CA1 region though aging and oxidative stress. J. Alzheimers Dis. 2005, 8, 299-309.

34. Heo, H.J.; Cho, H.Y.; Hong, B.S.; Kim, H.K.; Heo, T.R.; Kim, E.K.; Kim, S.K.; Kim, C.J.; Shin, D.H. Ursolic acid of Origanum majorana L. reduces A $\beta$-induced oxidative injury. Mol. Cells 2002, 13, 5-11.

35. Ikeda, Y.; Murakami, A.; Ohigashi, H. Ursolic acid: An anti-and pro-inflammatory triterpenoid. Mol. Nutr. Food Res. 2008, 52, 26-42.

36. Ma, C.M.; Cai, S.Q.; Cui, J.R.; Wang, R.Q.; Tu, P.F. The cytotoxic activity of ursolic acid derivatives. Eur. J. Med. Chem. 2005, 40, 582-589.

37. Zang, L.Y.; Cosma, G.; Gardner, H.; Shi, X.; Castranoval, V.; Vallyathan, V. Effect of antioxidant protection by $p$-coumaric acid on low-density lipoprotein cholesterol oxidation. Am. $J$. Physiol. Cell Physiol. 2000, 279, 954-960.

38. Luceri, C.; Giannini, L.; Lodovici, M.; Antonucci, E.; Abbate, R.; Masini, E.; Dolara, P. $p$-Coumaric acid, a common dietary phenol, inhibits platelet activity in vitro and in vivo. Br. J. Nutr. 2007, 97, 458-463.

39. Shin, K.Y.; Lee, G.H.; Park, C.H.; Kim, H.J.; Park, S.H.; Kim, S.H.; Kim, H.S.; Lee, K.S.; Won, B.Y.; Lee, H.G.; et al. A novel compound, maltolyl p-coumarate, attenuates cognitive deficits and shows neuroprotective effects in vitro and in vivo dementia models. J. Neurosci. Res. 2007, 85, 2500-2522.

40. Rice-Evans, C.A.; Miller, N.J.; Paganga, G. Structure-antioxidant activity relationships of flavonoids and phenolic acids. Free Radic. Biol. Med. 1996, 20, 933-956.

41. Heo, H.J.; Lee, C.Y. Protective effects of Quercetin and Viatamin C against oxidative stress-induced neurodegeneration. J. Agric. Food Chem. 2004, 52, 7514-7517.

42. Polewski, K.; Kniat, S.; Siawinska, D. Gallic acid, a natural antioxidant, in aqueous and micellar environment: Spectroscopic studies. Curr. Top. Biophys. 2002, 26, 217-227.

43. Leopoldini, M.; Marino, T.; Russo, N.; Toscano, M. Antioxidant properties of phenolic compounds: H-Atom versus electron transfer mechanism. J. Phys. Chem. A 2004, 108, 4916-4922.

44. Liu, Y.M.; Jiang, B.; Bao, Y.M.; An, L.J. Protocatechuic acid inhibits apoptosis by mitochondrial dysfunction in rotenone-induced PC12 cells. Toxicol. In Vitro 2008, 22, 430-437.

Sample Availability: Samples of the compounds used in this study are available from the authors.

(C) 2012 by the authors; licensee MDPI, Basel, Switzerland. This article is an open access article distributed under the terms and conditions of the Creative Commons Attribution license (http://creativecommons.org/licenses/by/3.0/). 